\title{
TOXIC MANIFESTATIONS OF OSMIUM TETROXIDE
}

\author{
BY
}

\author{
A. I. G. McLAUGHLIN, R. MILTON and KENNETH M. A. PERRY
}

From the University of Sheffield and Factory Department, Ministry of Labour and National Service, and the Department for Research in Industrial Medicine (Medical Research Council), the L.ondon Hospital

Osmium is one of the precious metals and was discovered in 1803 by Tenant. It occurs naturally in close association with iridium. Osmiridium is an exceptionally hard alloy with a high meltingpoint $\left(2700^{\circ} \mathrm{C}\right.$.) and for this reason it is used extensively for tipping fountain-pen nibs. It is also used for electrical contacts, as a catalyst in the preparation of synthetic ammonia, and for measuring the rapidity of explosion of gun-cotton. Before the introduction of tungsten, electric lamp filaments were sometimes made with it. Osmium is also used in the taking of finger-prints, and osmic acid which is a watery solution of osmium tetroxide is used for activating solutions of chlorate of potassium; hardening and colouring certain preparations and in histology for the fixing and staining of nerves and fat. The precious metals are likely to be used increasingly in the future and it is felt that the possible health risks in the use of their derivatives should be known at the outset.

\section{Review of Literature}

Metallic osmium is innocuous but osmium tetroxide is slowly formed on exposure of the spongy metal to air. The toxic properties of osmium tetroxide were first noticed by Gmélin (1827) who described the occurrence of vomiting when it was given by mouth. Intravenous injections in animals caused serous exudate from the lungs, three such injections producing paralysis and death. Vauquelin (1814), Berzélius (1828) and Wohlea (1834) drew attention to its corrosive action on the respiratory tract and eyes. Branell (1849) suggested that the symptoms resulted from the oxidizing action of osmium tetroxide $\left(\mathrm{OsO}_{4}\right)$ which is reduced to osmium dioxide $\left(\mathrm{OsO}_{2}\right)$, which is then hydrated $\left(\mathrm{OsO}_{2} 2 \mathrm{H}_{2} \mathrm{O}\right)$. Deville and Debray $(1859,1874)$ described how one of them was rendered almost blind for 24 hours when a current of air taking away vapour was thrown back unexpectedly on to him. It produced a sensation like a vigorous blow on the eye. Osmium tetroxide on the conjunctivae produced inflammation which continued to render sight troublesome for some weeks. The author also developed mild asthmatic symptoms and a co-worker a painful skin eruption. Raymond (1874) reports the only fatal case in the literature. The patient was employed by Vulpain in Paris and the vapours of osmic acid gave rise to a capillary bronchitis from which he died. Necropsy revealed a confluent broncho-pneumonia with a tendency to suppuration and gangrene; there was also a fatty degeneration of the epithelium of the renal tubules. Bardieux (1898) showed that the subcutaneous and intramuscular injection of a 1 per cent. solution of osmic acid produced no serious effect in animals but that small quantities injected into the lungs were immediately fatal. Attempts have been made to make use of the solution in treating diseases such as tuberculosis (Walbum, 1926), syphilis (Levaditi, 1927; and Jahnel, 1937) and cancer (Kraus, 1931) but without success, though Fischl (1933) showed it possessed some spirochaetocidal properties in experimentally infected mice Coca (1908) studied the effect of the substance on red blood cells, but the most comprehensive study of the toxicological properties of osmium tetroxide is by Brunot (1933). $\mathrm{He}$ exposed himself to some of the vapours and after 10 minutes he noticed a metallic taste in the mouth and found that smoking was unpleasant; after 30 minutes he noticed a smarting sensation in his eyes, lacrimation which was exaggerated by efforts to read; 3 hours later reading was difficult, he felt a definite constriction in the chest and found breathing also difficult; on going out into the street the lamps appeared to be surrounded by large haloes as if there were a dense fog. He therefore carried out animal experiments. Rabbits were exposed for 30 minutes in a box of 190 litres capacity. An ampoule containing $250 \mathrm{mg}$. of osmium tetroxide was placed in it on a hot plate and a fan was used to distribute it throughout the atmosphere. During the exposure the tetroxide was steadily reduced to the dioxide and metal so that at the end of the experiment only 10 per cent. was left. The muzzles of the animals became blackened; the pelt changed from white to dirty grey, and a brown film developed over the sclera and cornea. After 4 days the animals showed marked pulmonary embarrassment and when killed the lungs were voluminous and did not float in water. They were dark red and solid with scattered irregular purple areas and the bronchi were filled with pus. The kidneys showed cloudy swelling and granulation of the epithelium. After exposure to $500 \mathrm{mg}$. and $1 \mathrm{~g}$. the animals became semi-comatose a few minutes after the 
exposure, showed acute bronchial irritation and pulmonary embarrassment and died within 30 hours. He also placed 1 drop of 1 per cent. osmium tetroxide in water into the conjunctival sacs of rabbits. After 24 hours there was oedema and swelling of the lids with profuse purulent discharge and a metallic brown stain on all parts of the conjunctiva. After 48 hours the cornea was milky and semi-opaque with superficial conjunctival ulcers. Ten days after the exposure the acute stage had subsided, but there was corneal opacity and a pannus began to form which after 1 month slowly extended towards the centre of the cornea.

\section{Recent Investigation}

We had the opportunity of observing the effect of osmium tetroxide on seven men who were engaged in refining osmiridium. The findings appeared worth reporting. The atmospheric concentration of osmium tetroxide to which the men were exposed was estimated. This part of the investigation is described first, the clinical findings being given later.

\section{Environmental Study}

In dissolving ores containing the precious metals with aqua regia, osmium compounds are apt to gain access to the surrounding atmosphere in the fine spray which is given by the acid reaction. Samples of the air near to the action pots were obtained by sucking the air through a cone-shaped filter which was fitted with a low-resistance Whatman filter paper. Suction was obtained by means of an injector pump attached to an air line, and in the system was incorporated a flowmeter reading up to 100 litres per hour. Three 2-hour samples were taken during the reaction and distillation processes and estimated by the following method.

The paper containing the osmium in particulate form was gently boiled under reflux with $2.5 \mathrm{ml}$. of concentrated nitric acid for half an hour. Water was then added to the macerate until the solution was 10 per cent. with regard to nitric acid, and the volume was then about $25 \mathrm{ml}$. This solution was then transferred to an all-glass microdistillation apparatus and gently distilled into a receiver containing $3 \mathrm{ml}$. of concentrated hydrochloric acid saturated with sulphur dioxide. When about a fifth of the solution $(5.5 \mathrm{ml}$.) has been distilled, the distillation was terminated as all the osmium was by then removed. The solution in the receiver was estimated colorimetrically in the following way. To the solution was added $0 \cdot 1 \mathrm{ml}$. of 10 per cent. stannous chloride solution in 10 per cent. $\mathrm{HCl}$, $1 \mathrm{ml}$. of 2 per cent. gum ghatti solution, and $0.5 \mathrm{ml}$. of 10 per cent. aqueous thiourea solution. The mixture was then treated in a boiling water bath for 5 minutes, cooled and the pink colour which developed was read in the Spekker photoelectric absorptiometer fitted with a green filter. The result was referred to a calibration graph which was prepared by submitting standard solutions of osmic acid to a similar colorimetric technique. Alterna- tively a measurement can be made using a colorimeter if standard solutions of osmium are used in the comparison cell. Where very small quantities of osmium are encountered, a micro-technique may be employed, in which case the distillate may be arranged so that the osmium is contained in $2 \mathrm{ml}$. of liquid and colour development carried out as above, making certain that the concentration of acid in the distilling solution is of the order of 10 per cent. by volume. The colour is read in the Spekker absorptiometer fitted with micro cups, or in a microcolorimeter. This refinement was carried out when the osmium present was appreciably lower than $100 \mu \mathrm{g}$.

\begin{tabular}{cc}
\multicolumn{2}{c}{ CALIBRATION CURVE } \\
$\mu$ g. osmium & Spekker reading \\
0 & 0 \\
100 & 0.070 \\
200 & $0 \cdot 145$ \\
300 & 0.225 \\
400 & 0.300 \\
500 & 0.375 \\
600 & 0.450 \\
1000 & 0.750
\end{tabular}

ATMOSPHERE SAMPLES

(2-hour sample at 75 litres per hour $=150$ litres)

1. Osmium found $=20 \mu \mathrm{g}$. $133 \mu \mathrm{g}$ per cu. metre.

2. Osmium found $=70 \mu \mathrm{g}$. $\quad 467 \mu \mathrm{g}$ per cu metre.

3. Osmium found $=96 \mu \mathrm{g}$. $640 \mu \mathrm{g}$ per cu. metre.

\section{Clinical Picture}

The men exposed to these concentrations had symptoms similar to those described by Brunot (1933). They had irritation of the eyes with pain and lacrimation. They saw large haloes round all lights, one man saying they were green in the centre and red round the outside. Mostly the symptoms subsided within 24 hours. One of the men complained of bronchial irritation which caused a cough and thick sputum. The case histories of the seven men are as follows:

\section{Case Histories}

Case 1. A. A., aged 33, had during the whole of his working life been an analytical chemist in contact with osmiridium, for 12 years with one firm and for the last 4 years at the firm where these observations were made. He said that when he was in contact with osmium tetroxide, he notice his eyes were sore and ran freely and that if he looked at a light there was a large halo round it. He had a frontal headache. The symptoms usually wore off during the night and he was normal the next morning. He frequently had small ulcers in his mouth. He had no other symptoms. His only previous illness was scarlet fever as a child. Apart from a slight deformity of his chest he had no abnormal physical signs; blood pressure, 130/80; urine acid, specific gravity 1012 and contained no albumen or sugar. Blood count showed 5,950,000 red cells; 118 per cent. haemoglobin (alkaline haematin-photoelectric cell method $13.8 \mathrm{~g}$. of haemoglobin $=100$ per cent.); 7000 white cells; 60 per cent. polymorphs, 36 per cent. lymphocytes, 1 per cent. eosinophils and 3 per cent. monocytes.

Case 2. T. T., aged 45. Before the 1914-18 war he worked in an office. During that war he served in the army and since then he had worked in the chemical 
factory under observation, during the last 7 years. in contact with osmiridium. He noticed a smarting and running of his eyes and slight frontal headache. Later there was a gritty feeling in the eyes and 'conjunctivitis.' A halo appeared around everything he used, and he was unable to see the picture at the cinema. The headlights of an approaching car would appear to take up the whole road. He had no other symptoms, no previous illnesses, and physical examination revealed no abnormal physical signs; blood pressure, 140/98; urine acid, specific gravity 1030 , and contained no albumen or sugar. Blood count showed 5,600,000 red blood cells; 120 per cent. haemoglobin (alkaline haematin-photoelectric cell); 6200 white cells; 60 per cent. polymorphs 34 per cent. lymphocytes, 2 per cent. eosinophils and 4 per cent. monocytes.

Case 3. F. R., aged 53. He had been a gardener, and served in the army before joining the firm under observation. He had worked in contact with osmiridium for 18 years. When he went home after working with osmiridium, he noticed a halo around the moon and the stars and all other lights. His eyes smarted but did not run. He had no headache, and the next morning his eyes felt quite normal. He had no other symptoms, and had had no illnesses apart from trench fever during the last war. He had no abnormal physical signs; blood pressure, 140/110; urine acid, specific gravity 1024 , and contained no albumen or sugar. Blood count showed 5,000,000 red cells; 106 per cent. haemoglobin (alkaline haematin-photoelectric cell); 6000 white cells, 46 per cent. polymorphs, 49 per cent. lymphocytes, 4 per cent. eosinophils and 1 per cent. monocytes.

Case 4. J. K., aged 34. He had done general office work before joining this chemical firm 11 years ago. He had worked in contact with osmiridium during the past 18 months. He noticed that the osmium irritated his eyes and made them feel gritty. He had not noticed any running of the eyes. After the fusing of a charge, he noticed that there was a halo around all lights; these haloes had not disappeared by the next morning. $\mathrm{He}$ had no headache. He had no other symptoms. He had had measles and whooping cough as a child. On examination, apart from a small fatty hernia of the linea alba, there were no abnormal physical signs. His blood pressure was $110 / 80$. The urine was acid, specific gravity 1020, and contained no albumen or sugar. His blood count showed 5,200,000 red cells; 110 per cent haemoglobin (alkaline haematin-photoelectric cell); 13,000 white cells; 70 polymorphs, 26 per cent. lymphocytes, 1 per cent. eosinophils and 3 per cent. monocytes.

Case 5. E. J., aged 21, had worked at the firm for 5 years and had been in contact with osmiridium for 3 years. If the vapour of the tetroxide enters the workroom, it smells like garlic, it takes his breath away and produces irritating pains in the chest. It is difficult to breathe and he gets a cough with purulent sputum. He develops a halo around all lights, and this is green in the middle and red around the outside. The symptoms arise about two hours after contact and disappear after a night's sleep. He had no diplopia and no headache. He has no other symptoms; and apart from a mastoid operation 2 years ago, he has had no illness. He had no abnormal physical signs. The blood pressure was not taken and the urine was not examined. Blood count showed 5,800,000 red cells; 118 per cent. haemoglobin (alkaline haematin-photoelectric cell); 6400 white cells; 64 per cent. polymorphs, 34 per cent. lymphocytes, 1 per cent. basophils and 1 per cent. monocytes.

Case 6. F. T., aged 52. Apart from 4 years' service $n$ the army during the 1914-18 war, he had always worked at this firm. For 23 years he had been in contact with osmiridium. He had noticed a halo around all lights and a running of his eyes after he had been in contact with the substance. He could not read as the print appeared blurred. He had no headache. The symptoms had usually passed off by the next morning. He had no other symptoms and had not had any previous illnesses. He had no abnormal physical signs; blood pressure, 120/100; urine was acid, specific gravity 1020 , and contained no albumen or sugar. Blood count showed 5,750,000 red cells; 116 per cent. haemoglobin (alkaline haematin-photoelectric cell); 8400 white cells; 68 per cent. polymorphs, 27 per cent. lymphocytes, 1 per cent. eosinophils and 4 per cent. monocytes.

Case 7. C. M., aged 48. He had worked all his life with the same firm, and for the past 8 years had been in contact with osmiridium. If he handles osmium tetroxide, it causes his eyes to smart for the rest of the day and even the day following, but they do not water. He sees a halo around all lights and has a severe headache behind the eyes. He had had no previous illness, and showed no abnormal physical signs; blood pressure, $120 / 100$; urine was acid, specific gravity 1020 , and contained no albumen or sugar. Blood count showed $4,980,000$ red cells; 108 per cent. haemoglobin (alkaline haematin-photoelectric cell); 5800 white cells; 64 per cent. polymorphs, 32 per cent. lymphocytes, 1 per cent. eosinophils, 1 per cent. basophils and 2 per cent. monocytes.

\section{Eye Symptoms}

None of the seven men had eye symptoms at the time of the clinical examinations because they had not been working with osmiridium for some days. One case had a slight blepharitis; otherwise no abnormalities were detected. Arrangements were made for the men to be seen by Mr. A. B. Nutt, Ophthalmic Surgeon to the Sheffield Royal Infirmary, if at any time they had the characteristic eye symptoms. Two men went for examination and their eyes were examined with the slit-lamp microscope. On the cornea there appeared to be a number of minute doubly refractile areas, but the magnification of the microscope was not high enough for these areas to be identified with certainty. It was thought that they probably consisted of deposits of metallic osmium. Since then no cases of eye trouble have occurred because the fume of osmium tetroxide is now being removed from the workroom by mechanical ventilation.

Two men from the factory, however, volunteered to expose their eyes to the fume of osmium tetroxide and to undergo examination with a higher-powered slit lamp microscope. Nutt reported that the experiment was that of a man who brought some osmium and vaporized it in a small crucible held over a Bunsen flame; eye symptoms were produced in a very few minutes and again fine sparkling particles were noted on the surface of the cornea. If these were osmium crystals they might be expected to be very irritant. The appearance of these minute deposits of osmium on the cornea, even under high power, is however inconclusive; they sparkle as if they were crystalline but on examining them under a microscope nothing resembling osmium in a crystalline form could be found.

The characteristic symptoms are (i) a sensation of intense and sudden smarting of the eyes associated always with lacrimation and sometimes with frontal or orbital headache. (Histologists who use osmic acid as a myelin and fat stain are familiar with the headache which comes on if the bottle is 
left unstoppered on the bench.) In some cases there is a gritty feeling in the eyes together with injection of the conjunctivae. All seven of our cases vividly described the halo which appears round lights. They were unable to read or visit the cinema during the height of the symptoms.

\section{Nasal and Respiratory Symptoms}

The fume of osmium tetroxide has a sudden vigorous effect on the mucous membranes of the nose, throat and bronchi and has the characteristics of an irrespirable gas. It has a ' kick like a mule:' If fairly high concentrations are inhaled there is a sense of momentary constriction of the chest and inability to breathe. We tested this for ourselves by inhaling the fume coming from a bottle containing osmic acid (or a solution of osmium tetroxide). The sensation of irritation of the nose, throat and chest persisted for some 12 hours after only one such inhalation.

Of our seven cases, however, only one complained of cough with purulent sputum, and he had been working with osmiridium for 3 years.

\section{Prevention and Treatment}

The symptoms can be prevented by not allowing the fume of osmium tetroxide to enter the air of the workroom. When a new ventilating plant was installed over the reaction vessels at the factory where these men were employed no further symptoms were observed.

In most cases the symptoms subsided within 24 hours and were not severe enough to require treatment. But where treatment is necessary it should be directed to preventing infection. The sulphapyridin group of drugs or penicillin should be used for chest symptoms and a propamidine eye lotion for any conjunctivitis that might develop. Claus (1848) suggested the inhalation of hydrogen sulphide $\left(\mathrm{H}_{2} \mathrm{~S}\right)$ as an antidote and his suggestion has been repeated in many text-books. Obviously, such a ' cure' would be worse than the disease.

\section{Summary}

An account is given of a syndrome caused by the fume of osmium tetroxide evolved during the refining of osmiridium. It consisted of vigorous irritation of the conjunctivae and the mucous membranes of the nose, throat and bronchi, associated in some cases with frontal or orbital headache. The 'halo round lights' was a characteristic symptom resulting from the irritation of the eyes. It was temporarily disabling in that the worker was unable to read for about 24 hours. The men were exposed to concentrations of osmium tetroxide in the atmosphere up to $640 \mu \mathrm{g}$ per cubic metre. No chronic or cumulative effects were noted. Full details are given of the method used for the quantitative estimation of osmium.

We are indebted to the Sheffield Smelting Co. for allowing us to carry out this investigation, and to Mr. L. J. Young for his help and co-operation during the time the work was carried out. We also wish to thank Mr. A. B. Nutt for his valuable and willing co-operation in the investigation of the eye symptoms.

\section{REFERENCES}

Bardieux, J. B. (1898). Osmic Acid from Therapeutic Point of View.

Paris Thesis.

Branell, F. (1849). De acidi osmici in hominibus et animalibus effectu. Cascine.

Brunot, F. R. (1933). J. Industr. Hyg., 15, 136.

Claus, C. (1848). Bull. Acad. St. Petersburg, 6, 288.

Coca, F. (1908). Biochem Ztg., 14, 125.

Coca, F. (1908). Biochem Ztg., 14, 125 . 56,400 Deville and Debray (1859). Ann. de Che

Fischl, V. (1933). Z. Hyg. Infekthr., 114, 284.

Gmélin C. G (1827. Hyg. Infekthr., 114, 284.

Gmélin, C. G. (1827). Edin. J. Med. Sci., 3, 324

Jahnel, F. (1937). Z. Hyg., Infekthr. 119, 613.

Kraus, C. (1931). Arch. f. exper. path. u. pharm., 162, 452

Levaditi, C. (1927). Compt. Rend. Soc. biol., 97, 167.

Raymond, C. (1874) Mem. Soc. bio.
Tenant, S. (1804). Phil. Trans. 416 .

Tenant, S. (1804). Phil. Trans. 416.

Vauquelin, (1814), Ann. de chem, 89, 243.

Wohlea, (1834). Ann. der Pharm., 9, 152. 